\title{
Detection of postinfarction left ventricular aneurysms by first pass radionuclide ventriculography using a multicrystal gamma camera ${ }^{1}$
}

\author{
DUNCAN S. DYMOND, P. H. JARRITT ${ }^{2}$, K. E. BRITTON, AND R. A. J. \\ SPURRELL \\ From the Departments of Cardiology and of Nuclear Medicine, St Bartholomew's Hospital, West \\ Smithfield, London
}

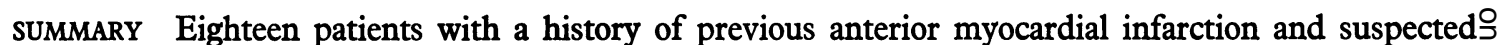
left ventricular aneurysms were studied both by contrast left ventriculography and by first pass radio- $\vec{c}$

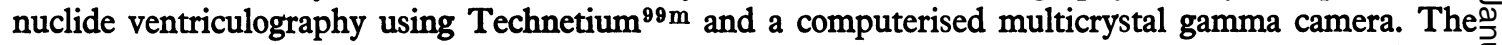
radionuclide study successfully identified all 14 patients with aneurysms and all 4 with diffusely hypo-@ kinetic ventricles. Ejection fraction calculated from the change in radioactive counts in the left ventricle ${ }^{\gtrless}$ correlated well with that calculated from the area-length method from the contrast angiogram $(r=0 \cdot 83) . \vec{\varphi}$

Ventricular volumes calculated from the area-length formula for both contrast and radionuclide. 0 angiograms correlated closely $(r=0.85$ and $r=0.89$ for end-systolic and end-diastolic volumes, respectively). In the 14 patients with aneurysms, there was a close correlation between the extent of akinesis, as assessed by the two methods $(r=0.94)$. The ability of the radionuclide ventriculogram to provide accurate information on global and segmental ventricular function, and to differentiate between $\frac{\Phi}{\varnothing}$ segmental and diffuse ventricular dysfunction, enables the method to act as a screening procedure in the $\underset{\rightarrow}{\stackrel{\varrho}{\rightarrow}}$ investigation of patients with suspected left ventricular aneurysms.

Left ventricular failure or congestive cardiac failure after myocardial infarction may be the result of a localised left ventricular aneurysm or of global ventricular hypokinesis (Bruschke et al., 1973). The differentiation between these two derangements of ventricular function is crucial in the assessment of such patients, as those with diffuse hypokinesis are rarely aided symptomatically by coronary artery bypass grafting or surgical resection. In addition, the operative mortality is high in this group, and operation is not recommended. Those with segmental dysfunction, however, are often candidates for surgical resection, and may show an improvement in left ventricular function after aneurysmectomy (Favaloro et al., 1968; Key et al., 1968; Graber et al., 1972; Mundth et al., 1972). The differentiation between diffuse and segmental disorders of ventricular contraction has been successfully accomplished for some years by

\footnotetext{
${ }^{1}$ This work was supported by the British Heart Foundation. 'Present address: Department of Nuclear Medicine, Middlesex Hospital, Mortimer Street, London WC1.
}

Received for publication 6 February 1978 cardiac catheterisation and contrast angiographyo (Baron, 1971; Hamilton et al., 1972).

Radioisotope techniques employing imaging of the radioactive cardiac blood pool at equilibrium, and using end-systolic and end-diastolic electro- 3 . cardiographic gating, have been previously reported as able to detect regional left ventricular dysfunction (Strauss et al., 1971; Zaret et al., 1971; Rigo et al.,응 1974). There are, however, some inherent disadvantages of these techniques, in particular theo high background counts within the other cardiac chambers, the need for electrocardiographic gating. devices, and limitation of choice of projection $N$ caused by inadequate separation of the cardiac ${ }_{\mathrm{W}}$ chambers in the right anterior oblique view.

Another approach to radionuclide cineangiography is the first pass technique, in which only $a_{\Phi}$ single pass of an intravenously injected bolus of a radionuclide is imaged in transit through the indi- 0 vidual cardiac chambers and lungs. In dynamico cardiac studies, three components in the resolution of an imaging system must be considered, (a) $\mathbb{Q}$ temporal, or the rate of framing, (b) spatial, and (c) statistical, or data density, and these components are not mutually independent. Fast framing rates too 
improve temporal resolution, without an increase in count rate capabilities, will decrease statistical accuracy and impair the ability of the system to detect abnormalities.

With conventional single crystal gamma cameras, the count rate and time-response capabilities are insufficient to provide statistically accurate data from the first pass. Though the count rates achieved may be sufficient to determine ejection fraction, they are often inadequate to define the ventricular borders precisely, or to analyse regional wall motion (Pitt and Strauss, 1977).

Using a multicrystal gamma camera (Bender and Blau, 1963), however, high count rate capabilities may be achieved (Grenier et al., 1974), with framing rates of 20 per second. The time resolution of 50 milliseconds is necessary to achieve accurate frames of each phase of the cardiac cycle. At longer count intervals, a frame that is designated end-diastole may already contain early systolic elements, and hence temporal resolution will be impaired. Such a combination of high temporal and statistical resolution allows accurate data to be acquired from the first pass.

This paper describes the results and correlations with cineangiographic data in 18 patients with suspected left ventricular aneurysms.

\section{Patients and methods}

Eighteen patients underwent cardiac catheterisation and left ventricular angiography for suspected left ventricular aneurysms. All had previously documented anterior myocardial infarctions. There were 15 men and 3 women, with a mean age of 57 years and a range of 44 to 69 years. The time elapsed from infarction to investigation was 1 month to 8 years, with a mean of 16 months and the principal reason for investigation was heart failure in 7 , angina pectoris in 7 , and ventricular arrhythmias in 4. All patients had a full clinical history taken and examination performed on admission, and all had standard 12 lead electrocardiograms and standard inspiratory upright posteroanterior chest $x$-ray films.

At cardiac catheterisation, contrast angiography was performed in the right anterior oblique projection. End-diastolic and end-systolic frames from the cineangiogram were visually selected, ignoring ectopic and immediately post-ectopic beats, and subsequently enlarged. The outline of the ventricular perimeters at end-diastole and end-systole were traced onto a graphic tablet with a pressure sensitive surface linked on-line to a computer (Honeywell DDP 516) which calculated the areas by an algorithm analogous to planimetry. The use of this system for measuring areas has already been des- cribed in another clinical context (Ward et al., 1976). The long axes of the ventricles and the length of the end-diastolic perimeters were measured also. End-diastolic and end-systolic volumes were then calculated from the prolate spheroid model formula for single plane right anterior oblique angiograms (Greene et al., 1967).

For the radionuclide study, the patient was positioned in the right anterior oblique projection, under the multicrystal detector of a Baird-Atomic system 77 gamma camera. An 18 gauge cannula was introduced into a medial vein of the cubital fossa under local anaesthetic, and attached to a $10 \mathrm{~cm}$ polyethylene tube with a $0.5 \mathrm{ml}$ capacity, separated by a three-way stopcock from a $20 \mathrm{ml}$ syringe full of normal saline. A bolus of high specific activity Technetium ${ }^{99 \mathrm{~m}}$, as pertechnetate, was injected with a rapid $20 \mathrm{ml}$ saline flush. The dose of radionuclide varied from 8 to $15 \mathrm{mCi}$, in a volume of 0.05 to $0.2 \mathrm{ml}$. The site of vein chosen is important, as injection of the bolus into lateral veins is associated with a longer path to the heart, and collateral vessels may conduct the bolus to the heart at different rates. Two or more separate components thus occur, with loss of bolus integrity (Watson et al., 1973).

One thousand frames of data were collected over a period of $\mathbf{5 0}$ seconds, that is at $\mathbf{5 0}$ millisecond framing intervals, to record the first pass of the bolus through the individual cardiac chambers and lungs. The data were recorded directly onto computer disc memory. This imaging system employs an array of 294 sodium iodide crystals arranged in a matrix of $14 \times 21$, and for the dynamic first pass studies a one-inch parallel hole collimator was used. The multicrystal detector achieves high photon count rates of 200000 counts per second (Schad, 1977). No electrocardiographic signal was recorded during the study.

After data acquisition, corrections for field nonuniformity and the dead-time of the instrument were applied.

The study was then played back as a sequential series of 12 images, showing the position of the bolus at 1.5 second intervals (Fig. 1), and a region of interest flagged to include the entire left ventricle. A high frequency histogram of counts against time for the left ventricular phase was generated (Fig. 2) to display the fluctuations in radioactive counts occurring with each heart beat. Each individual peak and trough represents the end-diastolic and end-systolic counts respectively for an individual cardiac cycle. The counts are proportional to the volume of the ventricle at any moment, and therefore ejection fraction may be calculated from the formula: 


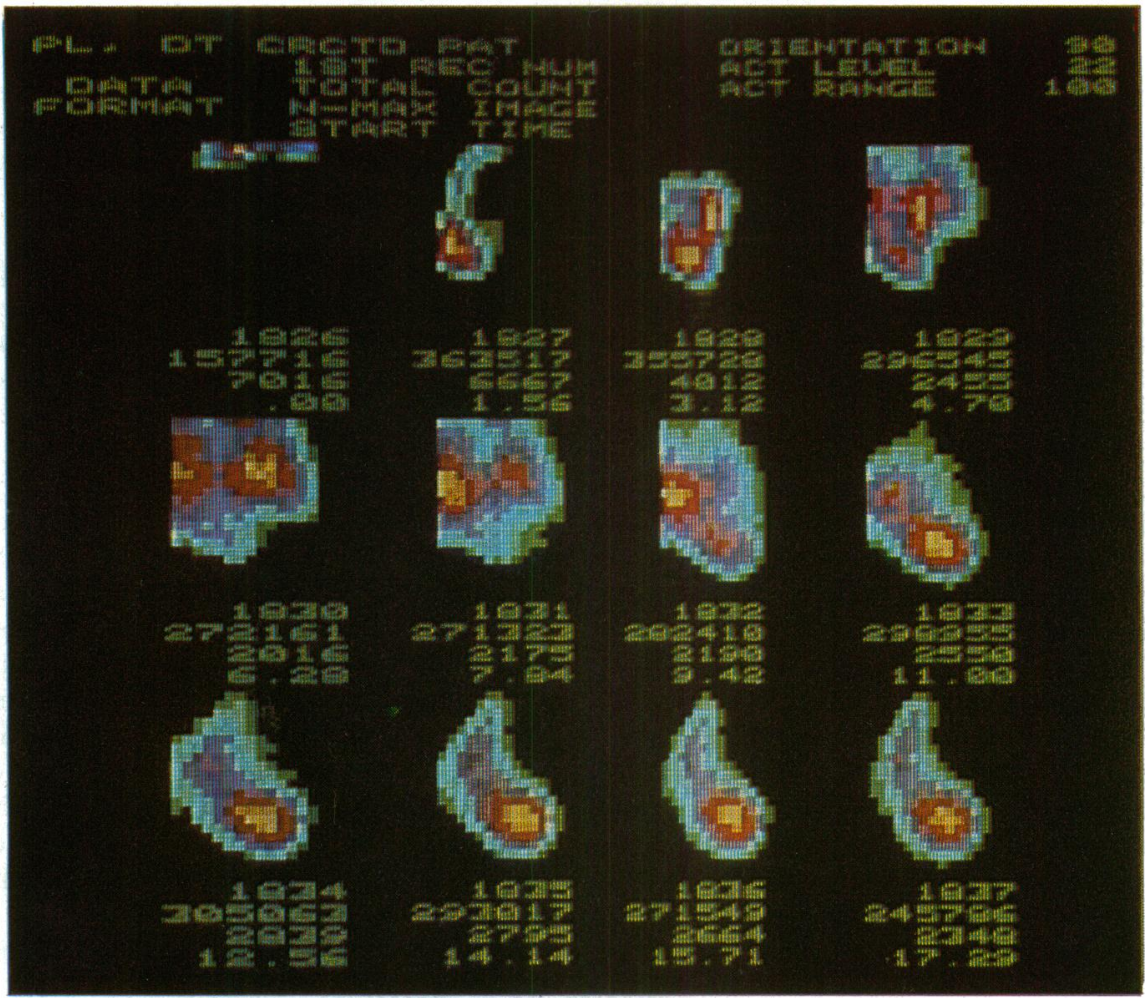

Fig. 1 Serial images at 1.5 second intervals after injection of the bolus, showing the passage of the bolus through the right heart and lungs (first 5 frames) and subsequent entry into the left atrium and left ventricle.

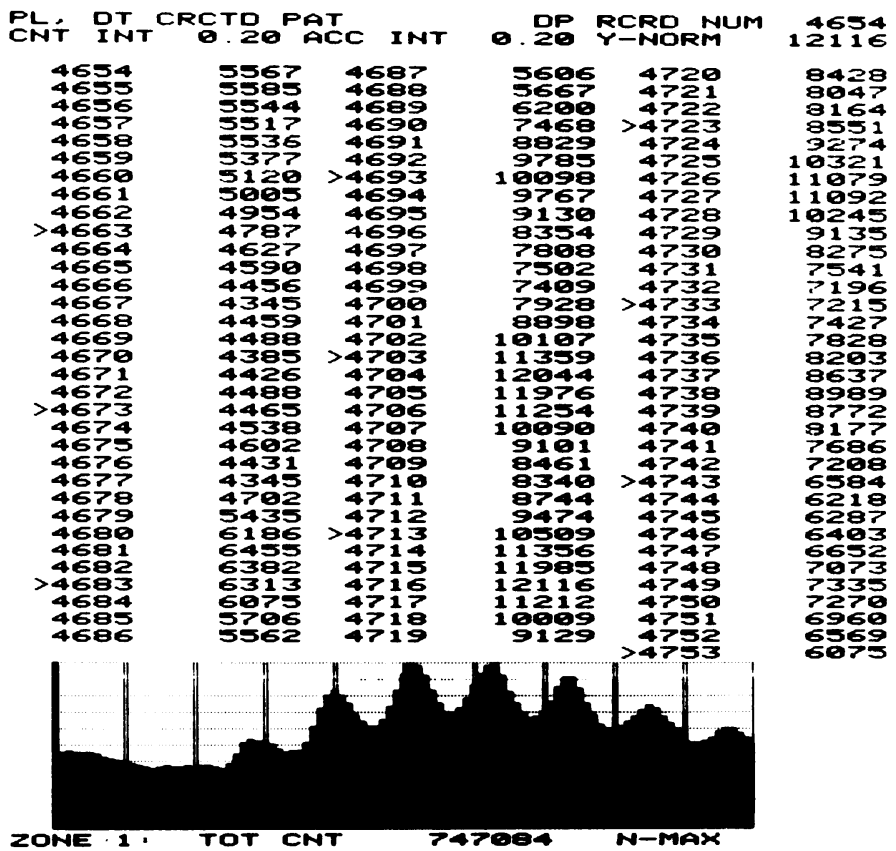

Fig. 2 High frequency time-activity histogram of counts in the left ventricle displayed at 50 millisecond intervals, over a period of 5 seconds. The arrows opposite the frame numbers and the thick vertical lines on the histogram represent 0.5 second intervals. N The background correction is obtained from the data before the appearance of the peaks and troughs (frames 4654-4673). End-diastolic frames used in ejection fraction calculation are $4693,4704,4716,4727$, and the end-systolic frames are 4686, 4699, $4710,4721,4732$. 
Ejection fraction $=$ end-diastolic counts in left ventricle - end-systolic counts in left ventricle, $\div$ end-diastolic counts in left ventricle - background counts.

The background correction was obtained from the frames of digital data approximately 0.5 seconds before the initial laevophase (Fig. 2) (Marshall et al., 1976). After ejection fraction calculation, the individual beats surrounding the peak of the histogram were summed by the computer, the number of beats usually varying from 4 to 8 . The summed cardiac cycles were then displayed as a cineangiogram of one average or representative cardiac cycle, allowing subsequent analysis of wall motion.

Single frames of the cine-cycle were then displayed as frozen images and processed by addition, subtraction, multiplication, or division with other frames, for generation of the perimeters of the ventricle, superimposition of the perimeters, or display of stroke volume distribution. No assumptions about ventricular shape are made during ejection fraction calculation.
The perimeters from the radionuclide ventriculogram were then traced onto the same pressure sensitive graphic tablet as those from the contrast angiograms, for computations of areas and lengths allowing ventricular volumes to be calculated.

The pattern of left ventricular contraction was analysed according to whether or not global or segmental dysfunction was present.

An aneurysmal ventricle was defined as one in which an akinetic segment could be shown, clearly demarcated from a contractile segment, in sinus rhythm. A diffusely hypokinetic ventricle was one in which poor wall motion occurred globally and where no clear-cut demarcation could be made between akinetic and non-akinetic muscle. In the group with left ventricular aneurysms, the extent of wall motion defect produced by the aneurysm was quantified for both contrast and isotope ventriculograms by expressing the length of the akinetic segment as a percentage of the total end-diastolic circumference of the ventricle (Feild et al., 1972). Thus the akinetic segment percentage (AS\%) =

Table Clinical, electrocardiographic, and chest $\mathrm{x}$-ray data from the 18 patients, with the angiographic and radionuclide classification of aneurysm or diffuse hypokinesis

\begin{tabular}{|c|c|c|c|c|c|c|c|c|c|c|c|}
\hline Case no. & $\begin{array}{l}\text { Time from } \\
\text { infarct to } \\
\text { investigation }\end{array}$ & $\begin{array}{l}\text { Main reason } \\
\text { for } \\
\text { investigation }\end{array}$ & $\begin{array}{l}\text { Abnormal } \\
\text { praecordial } \\
\text { impulse }\end{array}$ & $S_{\mathbf{8}}$ or $S_{\mathbf{4}}$ & $\begin{array}{l}\text { Systolic } \\
\text { murmur }\end{array}$ & $\begin{array}{l}\text { Site of } E C G \\
Q \text { waves }\end{array}$ & $\begin{array}{l}\text { Persistent } \\
\text { ST } \\
\text { elevation }\end{array}$ & $\begin{array}{l}\text { CTR } \\
>50 \%\end{array}$ & $\begin{array}{l}\text { Bulge } \\
\text { on } \\
\text { chest c } \\
\text { x-ray }\end{array}$ & $\begin{array}{l}\text { Aneurysm or } \\
(A) \\
\text { contrast }\end{array}$ & $\begin{array}{l}\text { Hypo- } \\
\text { kinesis }(H) \\
\text { radio- } \\
\text { nuclide }\end{array}$ \\
\hline 1 & 1 year & LVF & + & + & - & $V_{1}-V_{8}$ & + & + & - & A & A \\
\hline 2 & 6 months & Angina & $\div$ & + & - & $\begin{array}{l}\text { II, III, aVF } \\
\mathrm{V}_{2}-\mathrm{V}_{8}\end{array}$ & - & + & - & A & A \\
\hline 3 & 1 month & Angina & + & + & - & $v_{1}-v_{6}$ & + & + & - & A & A \\
\hline 4 & 2 months & $\begin{array}{l}\text { Recurrent } \\
\text { ventricular } \\
\text { tachycardia }\end{array}$ & - & - & - & $v_{1}-V_{4}$ & + & - & - & A & $\ddot{A}$ \\
\hline 5 & 5 months & Angina & + & + & + & $\mathrm{V}_{2}-\mathrm{V}_{5}$ & + & + & - & A & A \\
\hline 6 & 1 year & $\begin{array}{l}\text { Ventricular } \\
\text { tachycardia }\end{array}$ & - & - & - & $I, V_{2}-V_{6}$ & + & + & - & $\mathbf{A}$ & A \\
\hline 7 & 2 months & LVF & - & + & - & $\begin{array}{l}I_{1}, a V L \\
V_{2}-V_{6}\end{array}$ & + & - & - & A & A \\
\hline 8 & 4 months & Angina & + & + & - & $\begin{array}{l}\mathrm{I}, \mathrm{aVL} \\
\mathrm{V}_{4}-\mathrm{V}_{6}\end{array}$ & + & + & - & $\mathbf{A}$ & A \\
\hline 9 & 2 years & LVF & + & + & + & $V_{1}-V_{4}$ & + & + & - & A & A \\
\hline 10 & 2 months & $\begin{array}{l}\text { Ventricular } \\
\text { tachycardia } \\
\text { and fibrilla- } \\
\text { tion }\end{array}$ & + & + & + & $V_{1}-V_{6}$ & - & + & + & A & A \\
\hline 11 & 5 years & LVF & + & + & - & $\begin{array}{l}\mathrm{I}, \mathrm{aVL} \\
\mathrm{V}_{1}-\mathrm{V}_{6}\end{array}$ & + & + & + & A & $\mathbf{A}$ \\
\hline 12 & 8 years & Angina & + & + & + & $\begin{array}{l}\text { II, III, aVF } \\
\mathrm{V}_{2}-\mathrm{V}_{6}\end{array}$ & + & + & - & A & A \\
\hline 13 & 3 months & Angina & + & + & + & $\begin{array}{l}\text { I, aVL } \\
\text { V }_{1}-V_{6}\end{array}$ & + & + & + & A & $\mathbf{A}$ \\
\hline 14 & 18 months & LVF & - & + & + & $\begin{array}{l}\text { II, III, aVF } \\
\mathrm{V}_{3}-\mathrm{V}_{6}\end{array}$ & + & + & - & A & A \\
\hline 15 & 2 years & LVF & + & + & + & $\begin{array}{l}\text { RBBB } \\
\mathrm{V}_{1}-\mathrm{V}_{8}\end{array}$ & - & + & - & $\mathbf{H}$ & $\mathbf{H}$ \\
\hline 16 & 9 months & $\begin{array}{l}\text { Ventricular } \\
\text { fibrillation }\end{array}$ & - & + & - & $\begin{array}{l}\text { LBBB at } \\
\text { investigation }\end{array}$ & - & + & - & H & $\mathbf{H}$ \\
\hline 17 & 15 months & LVF & + & + & + & $\begin{array}{l}\text { II, III, aVF } \\
\mathrm{V}_{2}-\mathrm{V}_{8}\end{array}$ & + & + & - & $\mathbf{H}$ & $\mathbf{H}$ \\
\hline 18 & 1 year & Angina & - & + & + & $\begin{array}{l}\text { II, III, aVF } \\
\text { V }_{3}-V_{6}\end{array}$ & + & + & - & $\mathbf{H}$ & $\mathbf{H}$ \\
\hline
\end{tabular}

$S_{s} / S_{4}, 3$ rd or 4th heart sounds; CTR, cardiothoracic ratio; LVF, left ventricular failure; RBBB/LBBB, right or left bundle-branch block. 
(akinetic length of the end-diastolic circumference $\div$ end-diastolic circumference) $\times 100$.

All measurements were made in the right anterior oblique projection, and radionuclide studies were carried out within 6 hours before cardiac catheterisation in 14 patients, and within 24 hours in the remaining 4.

\section{Results}

\section{CLINICAL DATA}

The Table summarises clinical, electrocardiographic, and $x$-ray findings, along with the angiographic and radionuclide classification into the aneurysm group or hypokinesis group. Of the 14 patients with aneurysms 10 had abnormal praecordial cardiac impulses $(71 \%)$, while of the 4 with diffuse hypokinesis 2 had abnormal impulses (50\%) which would have been consistent with an aneurysm. On auscultation, 12 in the aneurysm group had either a third or fourth heart sound $(86 \%)$ and $6(43 \%)$ had apical systolic murmurs. All 4 with diffuse hypokinesis had third or fourth heart sounds, and $3(75 \%)$ had systolic murmurs.

All 14 in the aneurysm group had electrocardiographic evidence of previous anterior infarction, and 3 had evidence of additional inferior infarction. Persistent ST segment elevation of $1 \mathrm{~mm}$ or more in at least one electrocardiographic lead was present in $12(86 \%)$. Of those with diffuse hypokinesis, electrocardiograms showed anterior and inferior infarction in 2 , anterior infarction with right bundle-branch block in 1 , and at the time of investigation, left bundle-branch block in 1, though previous anterior myocardial infarction had been electrocardiographically documented. Two patients $(50 \%)$ had persistent ST segment elevation.

Chest $x$-ray films showed a cardiothoracic ratio of more than 50 per cent in 12 of the patients with aneurysms ( $86 \%)$, and 3 had a definite bulge on the cardiac silhouette suggesting an aneurysm. All 4 with diffuse hypokinesis had increased cardiothoracic ratios, but none had abnormal bulges.

At cardiac catheterisation, none of the 18 patients had significant mitral regurgitation on contrast angiography. All 14 with left ventricular aneurysms had aneurysms demonstrated by the first pass radionuclide study, and the latter successfully identified all with contrast angiographically proven diffuse hypokinesis.

Mean ejection fraction calculated from the change in radioactive counts in the left ventricle was 26 per cent, and that calculated geometrically from the contrast angiogram was 23 per cent. Fig. 3 shows graphically the correlations in ejection fraction, and even allowing for the difference in techniques,

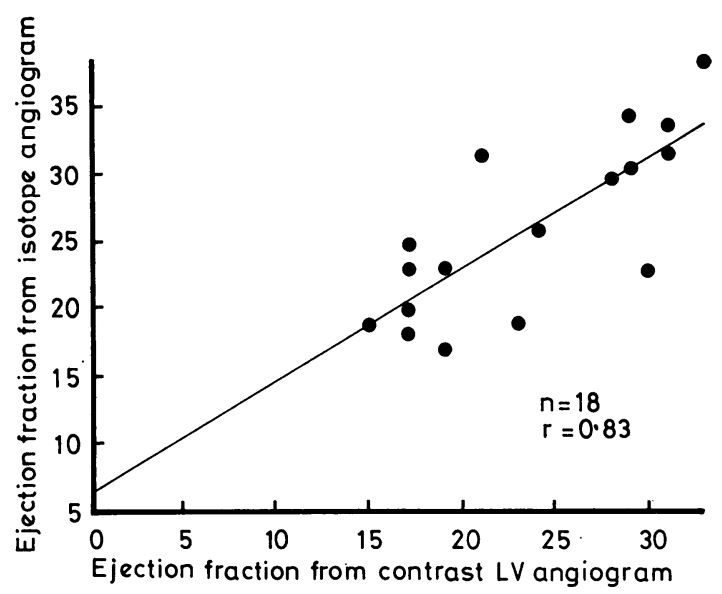

Fig. 3 Plot of left ventricular ejection fraction ( $L V E F)$ obtained by the area length method from contrast angiograms, versus radionuclide $L V E F$ obtained by changes in left ventricular counts.

and the low levels of ejection fraction in this group of patients, there is a significant correlation, with $r=0.83$. Only 17 points appear on Fig. 3, as 2 patients had identical ejection fractions from contrast and isotope studies, of 23 per cent and 17 per cent respectively, and thus 2 points are superimposed.

The patients with aneurysms could not be differentiated from those with diffuse hypokinesis on the basis of ejection fraction alone.

Fig. $4 \mathrm{a}$ and $4 \mathrm{~b}$ are examples of end-diastolic and end-systolic frames from the contrast angiogram of a patient with a ventricular aneurysm, together with the superimposed end-diastolic and end-systolic perimeters traced from the angiogram (Fig. 4c) and the superimposed perimeters from the first pass study in the same patient (Fig. 4d). In the isotope study, the purple perimeter represents end-systole and the white end-diastole. In both contrast and radionuclide studies there is inward motion of the ventricle apparent at the base of the heart but the perimeters show no motion anteroapically, providing the typical angiographic appearance of an anterior ventricular aneurysm.

Fig. 5a-d show the same sequence of information from a patient with diffuse hypokinesis. In both contrast and isotope studies poor inward wall $\stackrel{\oplus}{\rightarrow}$ motion is apparent globally, and no localised or 0 segmental defect is visible.

Actual stroke volume counts can be obtained by subtraction of end-systolic from end-diastolic counts. Further subtraction of the stroke volume counts from the end-systolic frame allows a visual representation of residual volume and stroke 

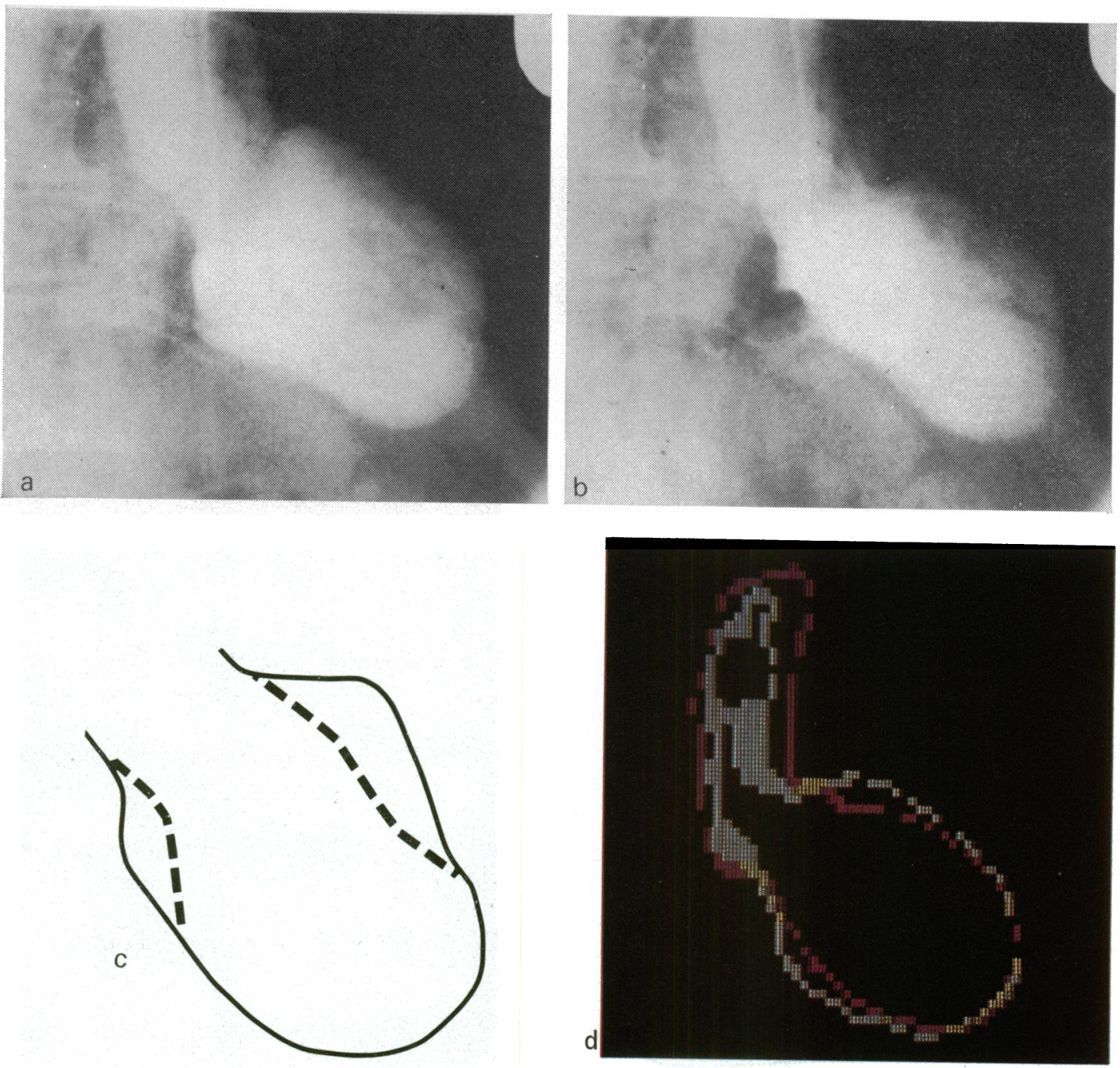

Fig. 4 (a) End-diastolic frame from cineangiogram of a patient with a left ventricular aneurysm. (b) Endsystolic frame from same cineangiogram. (c) End-diastolic (solid line) and end-systolic (dotted line) perimeters from the cineangiogram, traced and superimposed. (d) Superimposed end-diastolic (white) and end-systolic (purple) perimeters from the radionuclide angiogram of the same patient. Note the basal inward motion of the perimeters, with akinesis anteroapically, in both contrast and isotope studies.

volume distribution. Fig. 6 shows such data from a patient with an aneurysm and one with diffuse hypokinesis. The end-diastolic perimeter is added in each case. The dark areas inside the perimeter represent those areas from which the stroke volume has been ejected and the coloured areas the residual counts within the ventricle. The colour display of the system reproduces the activity distribution in 16 colour shades, from dark green $(6 \cdot 25 \%)$ to bright yellow (100\%).
The residual counts in the aneurysm example are apparent, situated in the apical segment of the ventricle only, while the basal segment is empty of counts. In the diffusely hypokinetic ventricle residual volume is evenly distributed, not segmentally. Such information on stroke volume distribution is able to provide additional data to that obtained from inspection of superimposed perimeters, as the latter reflects only two dimensional changes in ventricular wall position, whereas 

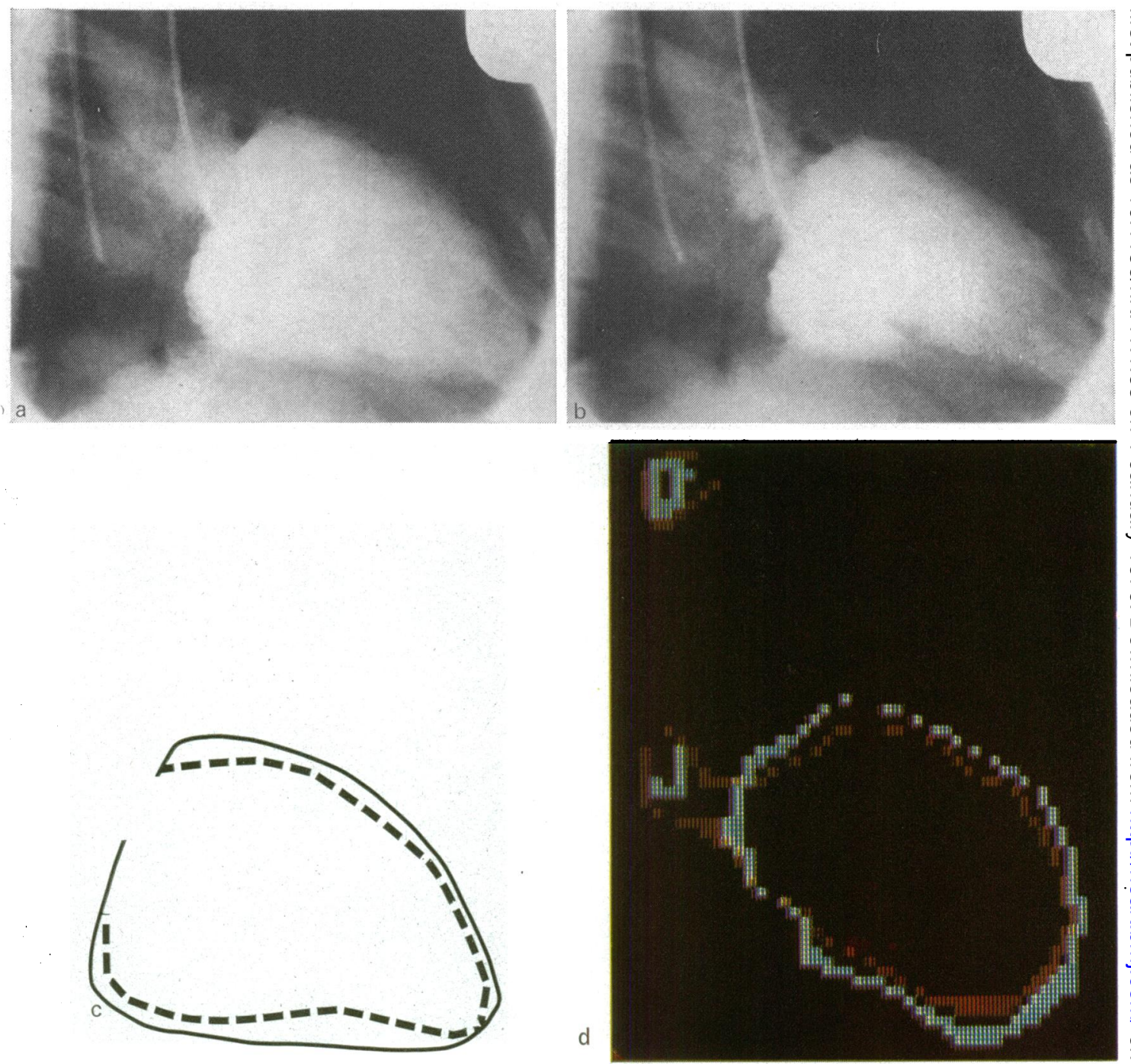

Fig. 5 (a) to 5 (d) Same sequence of data as in Fig. 4, for a patient with diffuse ventricular hypokinesis. Both contrast and radionuclide studies show generalised poor inward wall motion, with no segmental dysfunction.

stroke volume is in a three dimensional distribution, and contributions of other segments of the ventricle, not visualised in the right anterior oblique projection, to stroke volume may be assessed. This is apparent when one compares, for example, the radionuclide angiogram perimeters in Fig. $5 \mathrm{~d}$ with the stroke volume distribution in Fig. $6 \mathrm{~b}$.

In 17 patients in whom adequate measurements could be made, end-diastolic and end-systolic volumes were calculated from the traced perimeters of the isotope angiogram, using the area-length method and the known magnification factor for the multicrystal detector. The mean end-diastolic volume nuclide ventriculograms, respectively. Mean end- $N$ systolic volumes were $218 \mathrm{ml}$ and $234 \mathrm{ml}$, respectively. Fig. 7 shows the correlations between the volumes in graphic form, and though there is a $\mathbb{D}$ tendency for the isotope values to overestimate the volumes when compared with those from the contrast angiograms, the correlations are nevertheless $\underset{\mathbb{D}}{\mathrm{D}}$ significant, $\mathrm{r}=0.89$ and $\mathrm{r}=0.85$ for end-diastolic $\frac{\rho}{1}$ and end-systolic volumes, respectively, with re- $\stackrel{\mathbb{Q}}{\circ}$ gression equations of:

$y=0.92 x+38 \mathrm{ml}$ for end-diastolic volume $y=0.85 x+48 \mathrm{ml}$ for end-systolic volume. 

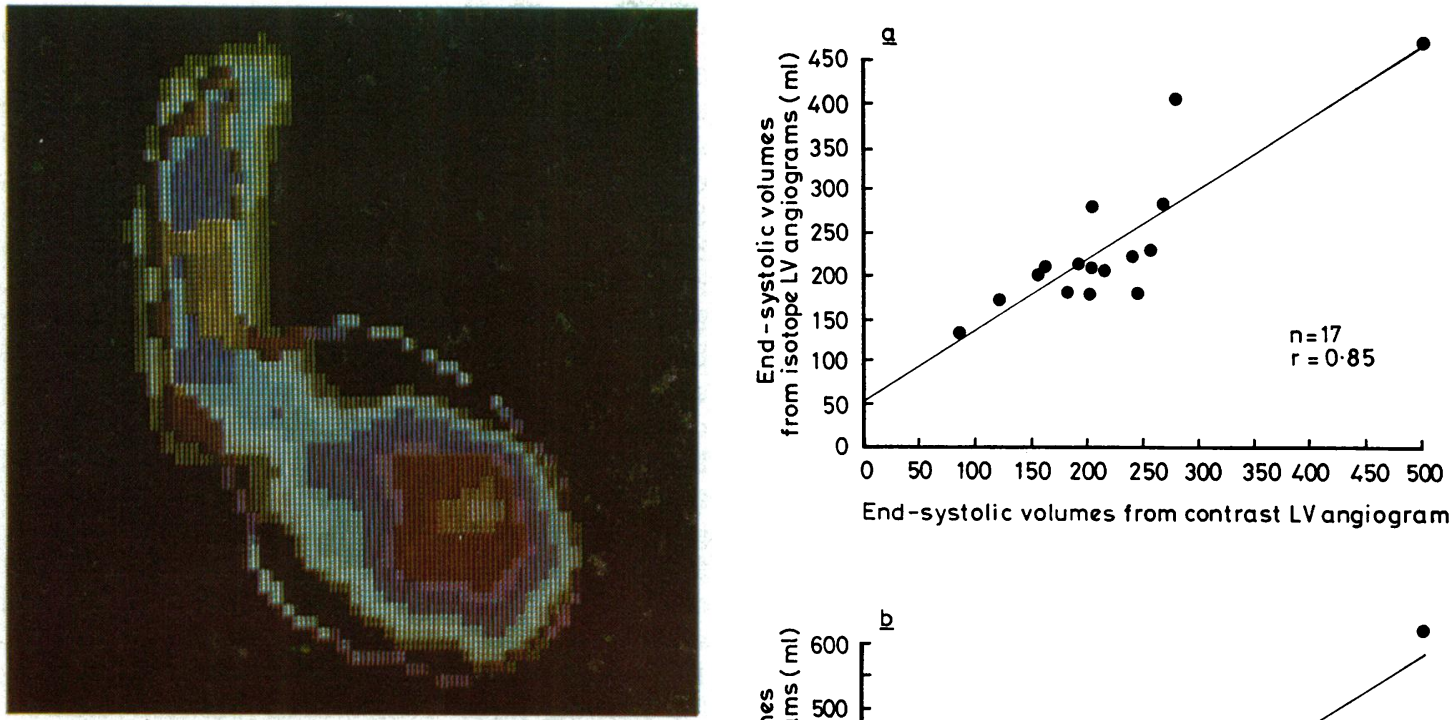

a

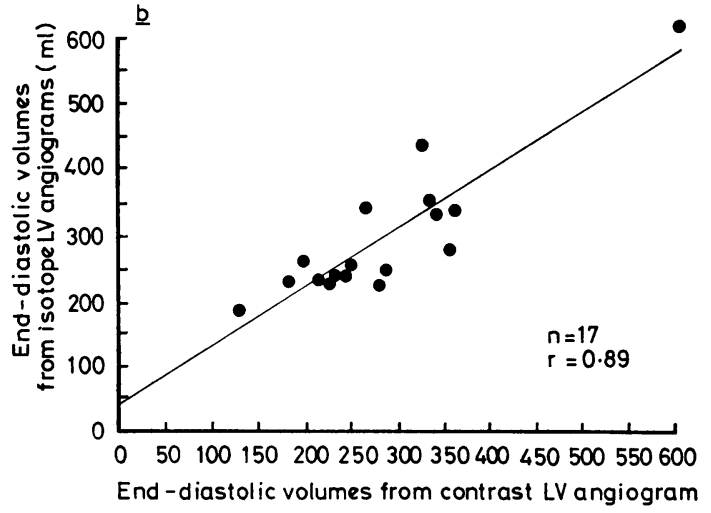

Fig. 7 (a) Plot of end-systolic volumes. (b) Enddiastolic volumes obtained from the area length method for contrast and radionuclide ventriculograms.

In the 14 patients with proven aneurysms, the extent of wall motion defect produced by the aneurysm was expressed, as outlined above, as a percentage of the total end-diastolic circumference.

Fig. 8 shows the correlation between the akinetic lengths for contrast and isotope ventriculograms which is extremely good, covering a range from 22 to 70 per cent of ventricular circumference, with $\mathbf{r}=0.94$.

\section{CORONARY ARTERIOGRAPHIC FINDINGS}

Fig. 6 (a) Stroke volume distribution in a patient with ventricular aneurysm. Stroke volume counts are subtracted from end-systolic counts, and end-diastolic perimeter (EDP) is added. The black areas inside the $E D P$ indicate the basal regions of ventricle from where counts have been removed, and the coloured area the distribution of residual volume, which here occupies the aneurysmal section only. (b) The same for a patient with diffuse hypokinesis. Stroke volume and residual distribution are of a non-segmental nature.

Of the 14 patients with ventricular aneurysms, all had either a completely occluded left anterior descending coronary artery or a severe stenosis of 80 per cent or more. Seven patients had single vessel disease, 1 had a blocked left anterior descending and an aneurysm of the circumflex artery, 2 had left anterior descending and right coronary artery lesions, and 4 had three-vessel disease. Selective coronary arteriography was performed in 


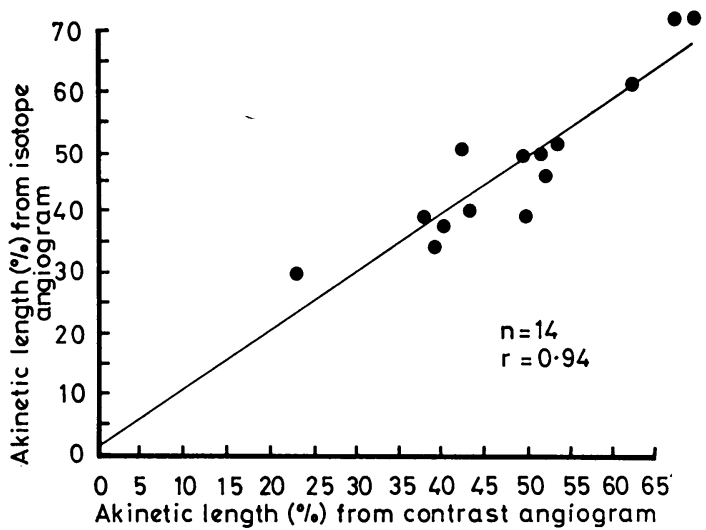

Fig. 8 Plot of extent of akinesis from contrast and radionuclide ventriculograms.

2 patients with diffuse hypokinesis, and both had three-vessel disease. In the other 2, cardiac catheterisation was terminated after the left ventricular angiogram had shown ventricular hypokinesis.

\section{Discussion}

The differentiation between segmental ventricular dysfunction and diffuse ventricular hypokinesis has for some years been successfully accomplished by cardiac catheterisation and selective left ventriculography (Baron, 1971; Hamilton et al., 1972). Recently, noninvasive techniques such as $\mathrm{M}$-mode echocardiography have been applied in attempts to diagnose left ventricular aneurysms (Dillon et al., 1976), though it is not yet proven that ventricular aneurysms may be differentiated from diffuse ventricular hypokinesis by this technique.

Detection of left ventricular aneurysms by gated blood pool scans has been previously described (Rigo et al., 1974) but the drawbacks to this particular approach to nuclear angiography are many. Imaging is only carried out at the extremes of the cardiac cycle, so much data are discarded. Electrocardiographic gating is employed, and imaging is carried out only during the immediate 40 milliseconds associated with end-systole, and 60 milliseconds associated with end-diastole (Zaret et al., 1971). As there is insufficient activity in any single brief period of imaging, the activity from several hundred cardiac cycles must be summed to achieve enough counts for statistical accuracy, and imaging may take up to 10 minutes. Numerous pitfalls may occur inasmuch as the patient may not be haemodynamically stable for that length of time, and if electrical and mechanical events become deranged, the exact siting of the electrocardiographic gate may be inaccurate, and may vary from one beat to another. Recent reports have described an extension of this simple gating to provide multiple $\frac{0}{0}$ gated blood pool imaging, allowing more of the $\overline{ }$ cardiac cycle to be displayed (Sneed et al., 1977; $\frac{\text { के }}{\circ}$ Strauss et al., 1977). Nevertheless, variations from $\stackrel{\square}{\unrhd}$ beat to beat in the association of electrical and $\triangleq$ mechanical events may still introduce an error. $\vec{P}$ Right anterior oblique imaging of the radioactive blood pool at equilibrium makes background $\vec{\omega}$

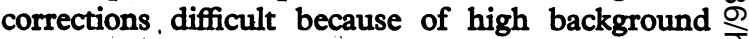
counts in the right ventricle lying anterior to the left ventricle, interfering with left ventricular count $\stackrel{\oplus}{\nexists}$ analysis. Since right anterior oblique cineangio- $\overrightarrow{-}$ grams are those most often employed when biplane $\infty$ facilities are not available, and since the right $ᄋ$ anterior oblique projection is superior to the left anterior oblique at detecting asynergy (Cohn et al., c) 1974), then right anterior oblique studies are optimal for allowing direct comparisons between contrast and radionuclide techniques in the detection and quantification of asynergy. The first pass radio- $\vec{\varphi}$ nuclide ventriculogram allows right anterior oblique projections to be performed with low back- : ground counts in the right ventricle, as the bolus will have been ejected from the right ventricle before entering the left. The first pass technique requires only 50 seconds for data acquisition and requires no $\stackrel{\unrhd}{\varrho}$ electrocardiographic gating, as end-diastolic and $\overrightarrow{\overrightarrow{0}}$ end-systolic frames are selected entirely by count $\frac{3}{3}$ density within the ventricle, as manifest by the peaks and troughs in the histogram of Fig. 2 . Patient stability is only necessary for the few cardiac cycles utilised in the first pass, and no assumptions are made as to the temporal relations of systole and diastole to electrical events.

The correlations in ejection fraction obtained (Fig. 3) are significant even at this low end of the spectrum of ventricular function, but nevertheless, despite the significant correlations, the graph shows a degree of scatter which can be accounted for, at least in part, by deviations from the prolate spheroid model of distorted and aneurysmal ventricles, and $\sigma$ subsequent errors in volume calculations from the $N$ contrast angiogram. Good correlations between $\underset{\omega}{N}$ ejection fractions calculated by such diverse methods have been previously reported (Sneed et al., 1977) though in this latter study comparisons were made between left anterior oblique radionuclide studies $\stackrel{?}{+}$ and right anterior oblique contrast films.

Calculation of absolute ventricular volumes from the radionuclide study requires the same assumptions about ventricular geometry as apply to the $\mathbb{D}$ contrast angiogram, and the same subjective outlining of perimeters. Nevertheless, by applying the prolate spheroid model to both techniques, how- 
ever invalid that model may be in this group of patients, the errors will apply to both techniques and should tend to cancel each other out. The correlations are significant (Fig. 7) though there is a tendency for the radionuclide study to overestimate the volumes compared with those from the contrast film. Small errors in choosing the exact edge of the ventricular outline will be cubed using the prolate spheroid model, and generation of the perimeters of the ventricle from the isotope study is achieved by edge enhancement of the activity at the left ventricular border. Small errors here will also compound the errors in volume calculation.

Despite these pitfalls, the isotope ventriculogram has yielded good correlations, similar to those reported by gated blood-pool scanning (Strauss et al., 1971).

Although ejection fraction and absolute volumes provide important information on global left ventricular function, they provide no information as to segmental function. Not only is the first pass radioisotope ventriculogram able to differentiate between aneurysmal and diffusely diseased ventricles, but is also able to quantify accurately the extent of wall motion defect present (Fig. 7). Our results are similar in this respect to those of Rigo et al. (1974). This simple index of extent of akinesis has been shown by others to have an important bearing on the presence or absence of heart failure (Feild et al., 1972), though it does not provide any information on the function of the residual, contractile segment of the left ventricle in patients with aneurysms, and there is evidence that function of the contractile segment is more important in determining the prognosis of aneurysmectomy (Arthur et al., 1972; Watson et al., 1975; Lee et al., 1977) than the actual size of the aneurysms.

Like many other groups we have found it difficult to separate patients with aneurysms from those with diffuse hypokinesis on the basis of clinical, electrocardiographic, or radiographic findings. Symptomatically, heart failure, angina, or ventricular arrhythmias occurred in both those with aneurysms and those with diffuse hypokinesis, as in the series of Rigo et al. (1974). Abnormal praecordial impulses were present in 10 of 14 patients with aneurysms, and 2 of 4 with diffuse hypokinesis, but the findings are too non-specific to be of any value in differentiation (Graber et al., 1972). Third and fourth heart sounds appear to be extremely common in patients with aneurysms, and also in those with diffuse hypokinesis (Table).

Persistent ST segment elevation occurred in $12 / 14(86 \%)$ of the aneurysms group, and $2 / 4$ $(50 \%)$ of those with diffuse hypokinesis. The numbers in this study are too heavily weighted in favour of patients with aneurysms to make statistical comparisons, but we did not find it a valuable electrocardiographic sign in the differentiation between the two groups, in common with the findings of others (Groden and James, 1969; Rigo et al., 1974). The size of the cardiac silhouette on chest $x$-ray film was abnormal in 86 per cent of the aneurysm group and 100 per cent of the diffusely hypokinetic group. It is of interest that the 2 patients with aneurysms and normal cardiothoracic ratios on $x$-ray film both had normal praecordial impulses, and one had no third or fourth heart sounds. The presence of a normal radiographic heart size with an angiographically proven aneurysm is well documented (Gorlin et al., 1967; Graber et al., 1972).

Although none of the 4 patients with diffuse hypokinesis had abnormal bulges seen on the plain chest $x$-ray film, only 3 of the aneurysm group $(21 \%)$ had such bulges. Our findings thus agree with those of Dubnow et al. (1965) in that routine chest $x$-ray films rarely lead to the diagnosis of ventricular aneurysms. Others, however, have noted a higher proportion of localised bulges (Mourdjinis et al., 1968; Graber et al., 1972). Cardiac fluoroscopy was not employed in the present study, but has previously been shown to be of little value in the exclusion of a ventricular aneurysm (Baron, 1971).

It is evident, therefore, that some sort of angiographic technique is essential in the differentiation of the two groups. The high count rate capabilities and rapid framing rates of the multicrystal gamma camera enable statistically accurate data to be achieved from the single passage of a radioactive bolus through the heart, without saturation of the crystals and the resultant random loss of counts. The patient's condition need not be stable for more than the few seconds required for the first pass, and right anterior oblique projections may be carried out with low background counts. Repeated views need a separate bolus of radionuclide, but even 2 doses of 10 millicuries each provide a radiation dose to the patient of less than 400 millirads compared with a dose of 3900 millirads for cardiac catheterisation and angiography (Gough et al., 1968). One drawback of the present technique is the high cost of the computerised multicrystal gamma camera, but the cost has to be offset against the savings achieved by demonstrating noninvasively that a particular patient has a nonsurgically treatable lesion. Other workers do not perform cardiac catheterisation and angiography on those patients with heart failure, in whom isotope ventriculography shows diffuse hypokinesis (Rigo et al., 1974), and such savings in terms of hospitalisation, catheterisation, and lack of ensuing morbidity are significant. 
We recommend the first pass radionuclide ventriculogram as a screening procedure in the precatheterisation phase of investigation of patients with symptoms occurring after infarction. It is not unreasonable to expect that in the future a large proportion of contrast angiograms will be replaced by this technique.

The authors wish to thank Mr David Franklin, of the Medical Computer Unit, St Bartholomew's, for his invaluable help.

\section{References}

Arthur, A., Basta, L., and Kioschos, M. (1972). Factors influencing prognosis in left ventricular aneurysmectomy (abstract). Circulation, 45 and 46, Suppl. II, 127.

Baron, M. G. (1971). Postinfarction aneurysm of the left ventricle. Circulation, 43, 762-769.

Bender, M. A., and Blau, M. (1963). The Autofluoroscope. Nucleonics, 21, 52-56.

Bruschke, A. V. G., Proudfit, W. L., and Sones, F. M. (1973). Progress study of 590 consecutive nonsurgical cases of coronary disease followed 5-9 years. II. Ventriculographic and other correlations. Circulation, 47, 1154-1163.

Cohn, P. F., Gorlin, R., Adams, D. F., Chahine, R. A., Vokonas, P. S., and Herman, M. V. (1974). Comparison of biplane and single plane left ventriculograms in patients with coronary artery disease. American fournal of Cardiology, 33, 1-6.

Dillon, J. C., Feigenbaum, H., Weyman, A. E., Corya, B. C., Peskoe, S., and Chang, S. (1976). M-mode echocardiography in the evaluation of patients for aneurysmectomy. Circulation, 53, 657-662.

Dubnow, M. H., Burchell, H. B., and Titus, J. L. (1965). Postinfarction ventricular aneurysm. A clinicomorphologic and electrocardiographic study of 80 cases. American Heart fournal, 70, 753-760.

Favaloro, R. G., Effler, D. B., Groves, L. K., Westcott, R. N., Suarez, E., and Lozada, J. (1968). Ventricular aneurysmclinical experience. Annals of Thoracic Surgery, 6, 227-245.

Feild, B. J., Russell, R. O., Jr., Dowling, J. T., and Rackley, C. E. (1972). Regional left ventricular performance in the year following myocardial infarction. Circulation, 46, 679689.

Gorlin, R., Klein, M. D., and Sullivan, J. M. (1967). Prospective correlative study of ventricular aneurysm. Mechanistic concept and clinical recognition. American fournal of Medicine, 42, 512-531.

Gough, J. N., Davis, R., and Stacey, A. J. (1968). Radiation doses delivered to the skin, bone marrow and gonads of patients during cardiac catheterisation and angiocardiography. British fournal of Radiology, 41, 508-518.

Graber, J. D., Oakley, C. M., Pickering, B. N., Goodwin, J. F., Raphael, M. J., and Steiner, R. E. (1972). Ventricular aneurysm. An appraisal of diagnosis and surgical treatment. British Heart fournal, 34, 830-838.

Greene, D. G., Carlisle, R., Grant, C., and Bunnell, I. L. (1967). Estimation of left ventricular volume by one-plane cineangiography. Circulation, 35, 61-69.

Grenier, R. P., Bender, M. A., and Jones, R. H. (1974). A computerised multicrystal scintillation gamma camera. In Instrumentation in Nuclear Medicine, vol. 2, pp. 101-134. Ed. by G. J. Hine and J. A. Sorensen. Academic Press, New York.

Groden, B. M., and James, W. B. (1969). Significance of persistent R-ST elevation after acute myocardial infarction.
British Heart fournal, 31, 34-36.

Hamilton, G. W., Murray, J. A., and Kennedy, J. W. (1972). Quantitative angiocardiography in ischaemic heart disease. 7 The spectrum of abnormal left ventricular function and the $\frac{C}{0}$ role of abnormally contracting segments. Circulation, 45, $\overline{\bar{c}}$ 1065-1080.

Key, J. A., Aldridge, H. E., and Macgregor, D. C. (1968). $\stackrel{\overparen{D}}{\varrho}$ The selection of patients for resection of left ventricular aneurysm. Fournal of Thoracic and Cardiovascular Surgery, 56, 477-483.

Lee, D. C. S., Johnson, R. A., Boucher, C. A., Wexler, L. F., and McEnany, M. T. (1977). Angiographic predictors of $\vec{\omega}$ survival following left ventricular aneurysmectomy. O Circulation, 55 and 56, Suppl. II, 12-18.

Marshall, R. C., Freedman, G. S., Costin, J. C., Cohen, L. S.,

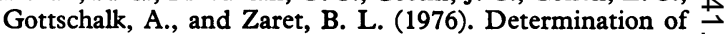
left ventricular ejection fraction and regional wall motion $-\overrightarrow{-}$ from first pass radionuclide angiocardiograms using a $\infty$ computerized multicrystal scintillation camera (abstract). fournal of Nuclear Medicine, 17, 555.

Mourdjinis, A., Olsen, E., Raphael, M. J., and Mounsey, J. P. D. (1968). Clinical diagnosis and prognosis of ventricular aneurysm. British Heart fournal, 30, 497-513.

Mundth, E. D., Buckley, M. J., Daggett, W. M., Sanders, ำ C. A., and Austen, W. G. (1972). Surgery for complica- $₹$ tions of acute myocardial infarction. Circulation, 45, 12791291.

Pitt, B., and Strauss, H. W. (1977). Evaluation of ventricular function by radioisotopic technics. New England fournal of Medicine, 296, 1097-1099.

Rigo, P., Murray, M., Strauss, H. W., and Pitt, B. (1974). Scintiphotographic evaluation of patients with suspected left ventricular aneurysm. Circulation, 50, 985-991.

Schad, N. (1977). Non-traumatic assessment of left ventricular wall motion and regional stroke volume after myocardial infarction. Fournal of Nuclear Medicine, 18, 333-341.

Sneed, A., Mishkin, F. S., Kaushik, V. S., and Reese, I. 3 (1977). Radionuclide cinecardiography using minicomputer generated sequential gated images. British Heart fournal, 39, 982-987.

Strauss, H. W., Singleton, R., Bureow, R., Rehn, T., Baily, I., จ্ণে and Pitt, B. (1977). Multiple gated acquisition (MUGA): @ an improved non-invasive technique for evaluation of regional wall motion (RWM) and left ventricular function LVF) (abstract). American fournal of Cardiology, 39, 284.

Strauss, H. W., Zaret, B. L., Hurley, P. J., Natarajan, T. K., 을 and Pitt, B. (1971). A scintiphotographic method for measuring left ventricular ejection fraction in man without $\mathrm{O}$ cardiac catheterisation. American fournal of Cardiology, 28, 575-580.

Watson, D. D., Nelson, J. P., and Gottlieb, S. (1973). Rapid 으․ bolus injection of radioisotopes. Radiology, 106, 347-352.

Watson, L. E., Dickhaus, D. W., and Martin, R. H. (1975). S Left ventricular aneurysm: preoperative hemodynamics, $N$ chamber volume and results of aneurysmectomy. Circula- N tion, 52, 868-873.

Ward, J. P., Franklin, D., and Wickham, J. E. A. (1976). A computer based technique for measurement of renal $O$ parenchymal area on intravenous urograms. British fournal $\frac{\mathrm{D}}{\mathscr{D}}$ of Radiology, 49, 836-839.

Zaret, B. L., Strauss, H. W., Hurley, P. J., Natarajan, T. K., and Pitt, B. (1971). A non-invasive scintiphotographic method for detecting regional ventricular dysfunction in $\mathrm{O}$ man. New England fournal of Medicine, 284, 1165-1170.

Requests for reprints to Dr Duncan Dymond, 울 Department of Cardiology, St Bartholomew's Hospital, London EC1A 7BE. 